\title{
Investigation of YAP/YAG powder sintering behavior using advanced thermal techniques
}

\section{Sintering to transparency}

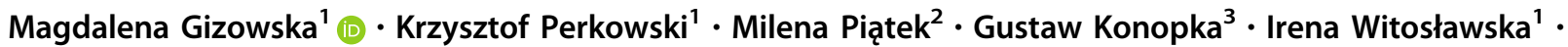 \\ Paulina Tymowicz-Grzyb ${ }^{3}$
}

Received: 1 December 2018/Accepted: 19 July 2019/Published online: 5 August 2019

(C) The Author(s) 2019

\begin{abstract}
The fabrication process of transparent $\mathrm{YAG}\left(\mathrm{Y}_{3} \mathrm{Al}_{5} \mathrm{O}_{12}\right)$ ceramics with an emphasis on examination of the sintering process and microstructural analysis is reported herein. Nanometric powder with an equivalent spherical diameter $d_{\mathrm{BET}}=60 \mathrm{~nm}$ consists mainly of hexagonal YAP phase $\left(\mathrm{YAlO}_{3}\right)$. According to sintering analysis carried out using a dilatometer and high-temperature XRD analysis, the phase composition and phase transformation taking place at elevated temperatures accompany the sintering process and the fastest sintering rate was observed at temperatures of YAG formation. Based on the dilatometric and XRD analyses vs temperature, three temperatures were selected for pressureless sintering. Presintered samples were subjected to sintering under isostatic pressure using a hot isostatic pressing, after which transparent YAG was obtained. The best results were obtained for samples presintered at a relatively low temperature of $1600{ }^{\circ} \mathrm{C}$, and for thus obtained sample, the in-line transmittance was $64 \%$ at $\lambda=808 \mathrm{~nm}$.
\end{abstract}

Keywords DIL · HIP · Transparent ceramics · XRD · YAG

\section{Introduction}

Yttrium aluminum garnet $\left(\mathrm{Y}_{3} \mathrm{Al}_{5} \mathrm{O}_{12}-\mathrm{YAG}\right)$ due to its unique properties finds application in various fields. Transparency in a wide spectrum range of electromagnetic radiation $(0.2-5.5 \mu \mathrm{m})$, a relatively high thermal conductivity in comparison with other oxide ceramics $\left(14 \mathrm{~W} \mathrm{~m}^{-1} \mathrm{~K}^{-1}\right.$ ) and the possibility of doping with rare earth elements predestine YAG for application in

Magdalena Gizowska

m.gizowska@icimb.pl

1 Division of Ceramic and Concrete in Warsaw, Department of Ceramics and Composites, Institute of Ceramics and Building Materials, 9 Postępu Street, 02-676 Warsaw, Poland

2 Division of Ceramic and Concrete in Warsaw, Research Laboratory, Institute of Ceramics and Building Materials, 4 Kupiecka Street, 03-042 Warsaw, Poland

3 Division of Ceramic and Concrete in Warsaw, Research Laboratory, Institute of Ceramics and Building Materials, 9 Postępu Street, 02-676 Warsaw, Poland optoelectronics as a matrix for laser active ions. The combination of excellent optical properties, stability at high temperatures and high hardness causes that YAG materials find application also in the refractory industry, e.g., as viewfinders.

In order to obtain transparent YAG, the material has to be of theoretical or near-theoretical density, and there are, generally, two paths. The first one involves the fabrication of single-crystals. The most popular method for YAG single-crystal fabrication is the Czochralski method [1]; for the smaller parts, micro-pulling-down technique, crucible laser heating pedestal method [2] and single-crystal growth from powder assisted by liquid phase [3] can be used. All methods for single-crystal fabrication are time-consuming and demand extreme temperatures, e.g., for Czochralski method, the crystal growth rate is about $2 \mathrm{~mm} \mathrm{~h}^{-1}$ and the melt has to be kept at temperatures above $1940{ }^{\circ} \mathrm{C}$.

Second approach for fabrication of transparent YAG materials involves the fabrication of a polycrystalline body with a porosity of less than $100 \mathrm{ppm}$ [4, 5]. There are 
numerous reports on the fabrication of YAG ceramics. Most of the presented methods involve the utilization of sintering aids such as silica, nanosilica [6, 7] or TEOS [8-11] and involve sintering for at least $10 \mathrm{~h}$ at temperatures above $1700{ }^{\circ} \mathrm{C}$.

Extensive research has been made on the fabrication of finely grained, transparent YAG ceramics using a toroidal high-pressure cell. The temperature of the process was $450{ }^{\circ} \mathrm{C}$ at a pressure of $2-8 \mathrm{GPa}[12,13]$. The densification process takes only $1 \mathrm{~min}$, but this method is limited to the fabrication of small parts.

The fabrication method of transparent polycrystalline YAG material with an emphasis on microstructural aspects is described herein. The nanopowder selected as a starting material was examined in terms of particle size distribution and phase composition. Dilatometric measurement of the sintering process was compared with high-temperature $\mathrm{XRD}$ analysis. For the densification of ceramics in postsintering process in hot isostatic pressing (HIP), it is crucial that only closed porosity is present in the ceramic body, i.e., the relative density is at least $90 \%$. Only then, the external pressure of argon causes pore closure due to the dissolution of gases encapsulated in pores into the ceramic material. In the HIP process also the enhanced rate of grain rearrangement may take place, which is effective in finely grained ceramic bodies.

\section{Materials and methods}

In the research, nanopowders of yttrium-aluminum garnet $\left(\mathrm{Y}_{3} \mathrm{Al}_{5} \mathrm{O}_{12}\right)$ provided by Nanocerox Inc. were used. The particle size was characterized by dynamic light scattering technique and calculated from the specific surface area measured by BET technique (Gemini VII, Micromeritics Instrument Corp.). Particle size distribution analysis was conducted by means of a zeta potential and particle size analyzer Zetasizer Nano ZS (Malvern Instruments Ltd, Worcestershire, UK) for diluted suspensions, which underwent ultrasonication (VibraCell VCX130, Sonics and Materials Inc., Newtown, USA) prior to measurement. The analysis results are presented in terms of $Z$ average $\left(Z_{\text {ave }}\right.$, also referred to as the cumulants mean or harmonic intensity averaged particle diameter) and polydispersity index (PdI), and these data are derived from the intensity of the overall mean particle diameter value and the overall average polydispersity, respectively. These are supported by median particle diameter $\left(d_{\mathrm{V} 50}\right)$.

The microstructure of powder and polished sintered ceramics was characterized by means of scanning electron microscopy (Nova NanoSEM 200, FEI Company).

$\mathrm{X}$-ray diffraction was performed in a Bragg-Brentano system using a diffractometer Bruker-AXS D8 DAVINCI equipped with a lamp with a copper anode. Diffractograms were recorded in the angular range of $5^{\circ}-120^{\circ} 2 \theta(\mathrm{Cu} \mathrm{K} \alpha)$, the measurement step was $0.01^{\circ}$, and time was $1 \mathrm{~s}$ per step. Identification of phases was performed by comparing the recorded diffraction patterns with patterns modeled in the database ICDD PDF-2 and PDF-4 + 2013 using DIFFRACplus EVA-SEARCH. When applicable, i.e., with main phases the content of which was above $5 \%$, the analysis of the crystallite size was based on the Scherrer formula using DIFFRACplus TOPAS v4.2. In other cases, the crystallite size was estimated by means of Lorentzian peak widening.

For phase analysis in a function of temperature, the diffractometer was equipped with a heating chamber. Diffractograms were recorded in the angular range of $14^{\circ}$ $65^{\circ} 2 \theta(\mathrm{Cu} \mathrm{K} \alpha)$, the measurement step was $0.02^{\circ}$, and time was $3 \mathrm{~s}$ per step. The sample was placed in a heating chamber in vacuum on platinum-rhodium tape joined with a type $S$ thermocouple. The measurements were taken in selected temperatures within the range of $35-1600{ }^{\circ} \mathrm{C}$. The quantitative analysis was conducted by Rietveld method using TOPAS v4.2, and the quantity of the amorphous phase was not measured.

For sintering investigations, powders were granulated with addition of a binder (water solution of polyvinyl alcohol-Optapix, Zschimmer \& Schwarz, Germany) and plasticizer (water solution of polyethylene glycol; $M_{\mathrm{w}}=1500$; Aldrich) and uniaxially pressed in ceramic molds into cylindrical samples with a diameter of about $16 \mathrm{~mm}$ and a height of $2.3 \mathrm{~mm}$. The green bodies were isostatically densified in a cold isostatic press at a pressure of $250 \mathrm{MPa}$ to an average relative density of $51.2 \%$ (standard deviation $=0.5 \%$ ). Thus, obtained samples were subjected to two-step sintering process: pressureless sintering in air atmosphere and sintering in conditions of high temperature and pressure of inert gas (argon) using a hot isostatic pressing (HIP).

The measurement of linear changes of pressed granulates was taken using a Netzsch high-temperature dilatometer (model Dil 402E) equipped with a graphite furnace. For the dilatometric measurement, a cylindrical sample of $6.56 \mathrm{~mm}$ in height and $5.5 \mathrm{~mm}$ in diameter was prepared from the granulate prepared as described above. The measurement was taken in a temperature range of RT to $1750{ }^{\circ} \mathrm{C}$ with a temperature gradient of $5{ }^{\circ} \mathrm{C} \min ^{-1}$ in helium flow.

Prior to the dilatometric measurement, calibration was carried out with a graphite standard of known properties and expansion. The measurement was taken under the same conditions (temperature heating program, atmosphere, gas flow rate) in order to determine the signals related to the expansion of the device elements and to correct the results obtained during the proper measurement. 
Density and open porosity of sintered bodies were measured by Archimedes method. The results were averaged, and standard deviation was calculated based on the measurements of nine samples.

In order to characterize the microstructure of the obtained YAG ceramics, samples were axially cut, polished and thermally etched to reveal the grain boundaries. Microstructure was analyzed by scanning electron microscopy. Two-dimensional microstructure SEM images were used to estimate grain size. The diameter of grains was described by projected area diameter $\left(d_{2}\right)$, which is the diameter of a circle having the same area as that projected by the particle [14]. The area of the grains was determined using AxioVision LE64 (Carl Zeiss Microscopy GmbH). The grain size statistics was made by number $\left(d_{\mathrm{n}}\right)$.

Transparency of the obtained ceramics was evaluated using Spectrum One CCD detection system. (The research was carried out at the Institute of Physics PAS.)

\section{Results and discussion}

\section{Powder characterization}

In Fig. 1, images obtained by SEM of the YAG powder used in the research are presented.

According to SEM observations, the powder occurs as in micron-sized agglomerates consisting of fine, globular nanoparticles (Fig. 1). The measurements of crystallite size showed that the crystallites $\left(d_{\text {cryst. }}\right)$ are below $50 \mathrm{~nm}$ (Table 2). The specific surface of the powder is relatively high $\left(22.09 \mathrm{~m}^{2} \mathrm{~g}^{-1}\right)$, and the calculated BET spherical particle diameter is $60 \mathrm{~nm}$. The dynamic light scattering measurement of particle size provides information about particles of median diameter $d_{\mathrm{V} 50}=382 \mathrm{~nm}$ and cumulants mean $Z_{\text {ave }}=406 \mathrm{~nm}$ (Table 1$)$.

There are significant discrepancies between the values of $d_{\mathrm{BET}}, d_{\mathrm{V} 50}$ and $d_{\text {cryst. }}$, which result from the different
Table 1 Results of particle size analysis obtained by specific surface area technique and dynamic light scattering of YAG powder

\begin{tabular}{lllll}
\hline $\mathrm{S}_{\mathrm{BET}} / \mathrm{m}^{2} \mathrm{~g}^{-1}$ & $\mathrm{~d}_{\mathrm{BET}} / \mathrm{nm}$ & $\mathrm{Z}_{\text {ave }} / \mathrm{nm}$ & PdI width/nm & $\mathrm{d}_{\mathrm{V} 50} / \mathrm{nm}$ \\
\hline 22.09 & 60 & 406.0 & 226.5 & 382 \\
\hline
\end{tabular}

$Z_{\text {ave }}$ cumulants mean, $P d I$ polydispersity width, $d_{\mathrm{v} 50}$ median diameter of the particle size distribution, $S_{\mathrm{BET}}$ specific surface area, $d_{\mathrm{BET}} \mathrm{BET}$ equivalent spherical particle diameter

nature of the measurements. The crystalline size estimated by XRD gives information about the average size of regions of the same crystallite structure [15]. This value is always smaller than the measurements estimated by imaging techniques due to the presence of disordered matter at the surface of nanoparticles [16, 17].

Calculation of $d_{\mathrm{BET}}$ produces information about the average size of primary particles visible in SEM imaging. However, the nanoparticles occur in a form of agglomerates, which are stable in water and remain in a slightly agglomerated state even after ultrasonification. The measured value is the hydrodynamic diameter, which means that the diameter is enlarged by the layer of solvent particles stiffly adsorbed at the particle surface. This layer can be significant in the case of nanoparticles due to their high surface energy.

Surprisingly, commercially available powder described as YAG in reality consists mainly of hexagonal YAP phase $(82 \%)$ and regular YAG phase that makes up only about $6 \%$ of the powder (Table 2). Additionally, monoclinic YAM, $\gamma$-alumina and other phases are present in quantities of a few percent. The presence of YAP, YAM and YAG phases indicates that the powder was produced in an environment with inhomogeneous temperature distribution as YAM phase is formed in temperatures of about $900{ }^{\circ} \mathrm{C}$ and YAP-above $1000{ }^{\circ} \mathrm{C}$ [18-20].
Fig. 1 Scanning electron microscopy images of YAG $\left(\mathrm{Y}_{3} \mathrm{Al}_{5} \mathrm{O}_{12} ;\right.$ Nanocerox Inc.)
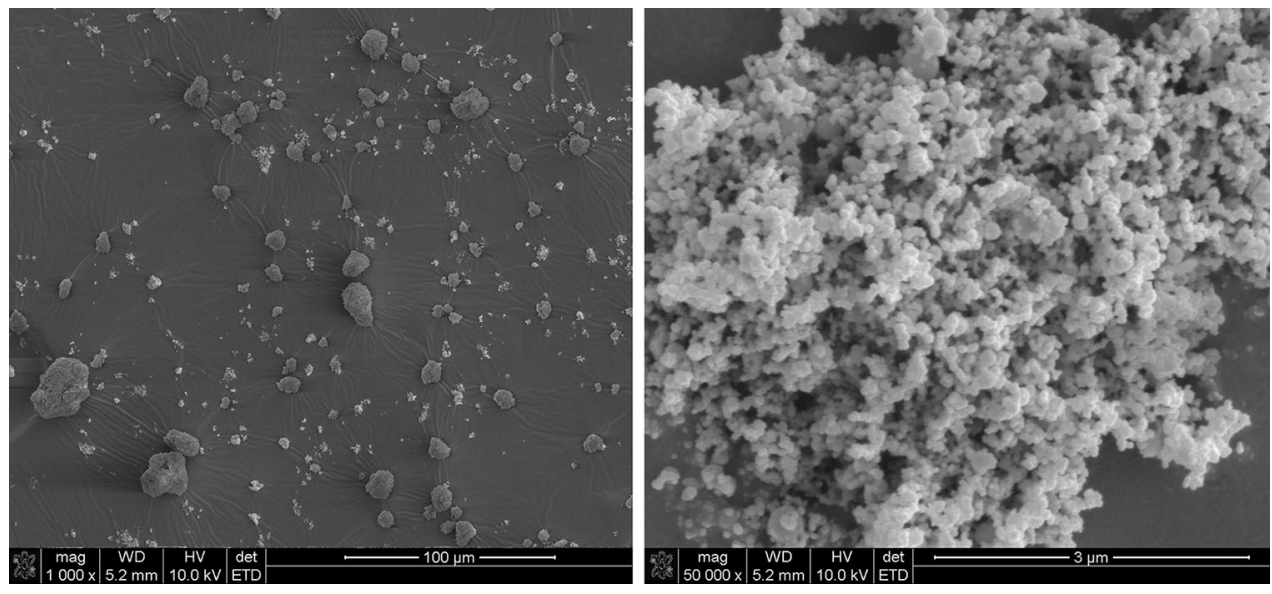
Table 2 Phase composition of YAG powder

\begin{tabular}{lcl}
\hline Phase composition & & \\
\hline Identified phase & Mass/\% & $d_{\text {cryst. }} / \mathrm{nm}$ \\
\hline $\mathrm{YAlO}_{3}-\mathrm{YAP}$ & $81.74 \pm 0.71$ & $36.01 \pm 0.71$ \\
$\mathrm{Y}_{3} \mathrm{Al}_{5} \mathrm{O}_{12}-\mathrm{YAG}$ & $6.08 \pm 0.30$ & $15.9 \pm 1.2$ \\
$\mathrm{Y}_{4} \mathrm{Al}_{2} \mathrm{O}_{9}-\mathrm{YAM}$ & $3.64 \pm 0.26$ & $67 \pm 10$ \\
$\gamma-\mathrm{Al}_{2} \mathrm{O}_{3}$ & $5.61 \pm 0.66$ & $19.4 \pm 3.7$ \\
$\mathrm{Y}_{0.497} \mathrm{Al}_{11} \mathrm{O}_{17}$ & $0.764 \pm 0.077$ & 45.0 \\
$\mathrm{Y}_{3} \mathrm{O}_{4}$ & $2.17 \pm 0.22$ & $28.0 \pm 5.7$ \\
\hline
\end{tabular}

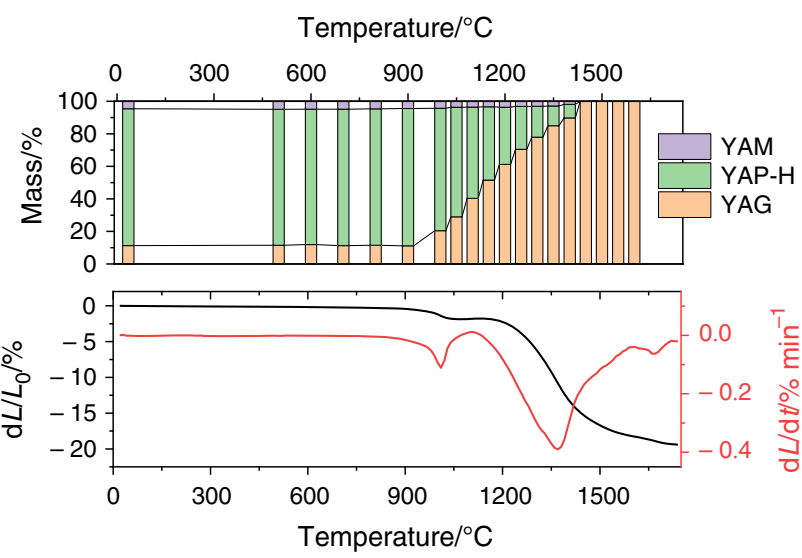

Fig. 2 Phase content in a function of temperature from XRD measurement in a heating chamber (upper graph) and dilatometric curve and its derivative (lower graph)

\section{Investigation of sintering process}

The assumption was made to design a transparent YAG fabrication method with the aid of hot isostatic pressing (HIP) without the encapsulation process. HIP process is effective only if the processed body reaches a density of $\min .90 \%$, then it is guaranteed that the residual porosity is an open porosity and does not interfere with the densification of the body [21, 22]. For this reason, the presintering process was thoroughly investigated. In Fig. 2, the results of the phase analysis measured in situ inside a heating chamber and the dilatometric curve are presented.

In the phase content vs temperature graph (Fig. 2), only main phases are shown. The phase composition remains constant up to a temperature of $900{ }^{\circ} \mathrm{C}$. At a temperature of $1000{ }^{\circ} \mathrm{C}$, a decrease in the YAP phase amount is observed; instead, YAG phase is formed. With further increase in temperature, the amount of YAG phase increases in an approximately linear manner. Above a temperature of $1350{ }^{\circ} \mathrm{C}$, the process continues together with a decay of YAM phase. At a temperature of $1450{ }^{\circ} \mathrm{C}$, only YAG phase is observed. Phase transformation temperatures are lower than those reported for the reaction between $\mathrm{Al}_{2} \mathrm{O}_{3}$ and $\mathrm{Y}_{2} \mathrm{O}_{3}$ powders $[20,23]$, as the powder used in the experiments was mixed on the atomic level, and less energy was needed for atomic diffusion in comparison with energy needed for atomic diffusion in a mixture of alumina and yttria powder.

The dilatometric curve shows that the sintering process proceeds in three stages and partly corresponds to the phase transformations (Fig. 2).

The first sintering step starts at temperature of $968{ }^{\circ} \mathrm{C}$ with maximum linear change rate at a temperature of $1011{ }^{\circ} \mathrm{C}$ and linear change of $1.6 \%$. The YAP phase decay starts in the same temperature range. The second sintering step begins at a temperature of $1255^{\circ} \mathrm{C}$ with the maximum linear change rate at a temperature of $1369{ }^{\circ} \mathrm{C}$ and is accompanied with the most intensive sintering effect $(\mathrm{d} L /$ $\left.\mathrm{d} L_{0}=16.5 \%\right)$.

The densities of the YAG, YAP and YAM phases calculated from the crystal structure measured in XRD analysis are, respectively, 4.5218, 4.5208 and $4.4337 \mathrm{~g} \mathrm{~cm}^{-3}$. Although YAP and YAM phases are of lower densities, based on this data, the rough estimation of the overall linear change calculated from the volumetric change of the phases is $4 \%$. Therefore, it can be concluded that the shrinkage observed in the temperature range of $1000-1450{ }^{\circ} \mathrm{C}$ results only in minor part from phase transformation and the sintering process is predominant. The process has the characteristics of reactive sintering.

A similar behavior was observed in other works concerning phase transformation-assisted sintering not only of YAP, but $\gamma$-alumina and anatase as well [24-27]. According to these works, enhanced sintering rates occurring at temperatures of phase transformation result from increased mobility of atoms due to the bound breakage. Additionally, phase transformations of grains cause a reduction in their volume. The shrinkage of grains can lead to their rearrangement and their better packing [24, 27].

In the temperature range of $1605-1726^{\circ} \mathrm{C}$, the last sintering step is observed with a linear change of $1.0 \%$ and the maximum sintering rate temperature of $1667{ }^{\circ} \mathrm{C}$. According to phase content vs temperature analysis in this temperature range, no phase transformation takes place, and thus, the observed shrinkage can contribute to grain growth [28]. Approximated temperature values

Table 3 Selected physical properties of YAG samples after pressureless sintering

\begin{tabular}{lll}
\hline Sintering temperature & $d_{\text {rel. }} / \%$ & $P_{\mathrm{o}} / \%$ \\
\hline $1600{ }^{\circ} \mathrm{C}$ & $93.6 \pm 1.4 \%$ & $1.09 \pm 0.6 \%$ \\
$1670{ }^{\circ} \mathrm{C}$ & $98.1 \pm 1.6 \%$ & $0.45 \pm 0.34 \%$ \\
$1700{ }^{\circ} \mathrm{C}$ & $98.0 \pm 1.0 \%$ & $0.93 \pm 0.35 \%$ \\
\hline
\end{tabular}


Table 4 Microstructure, grain and pore size distribution by number of YAG samples after pressureless sintering in selected temperatures

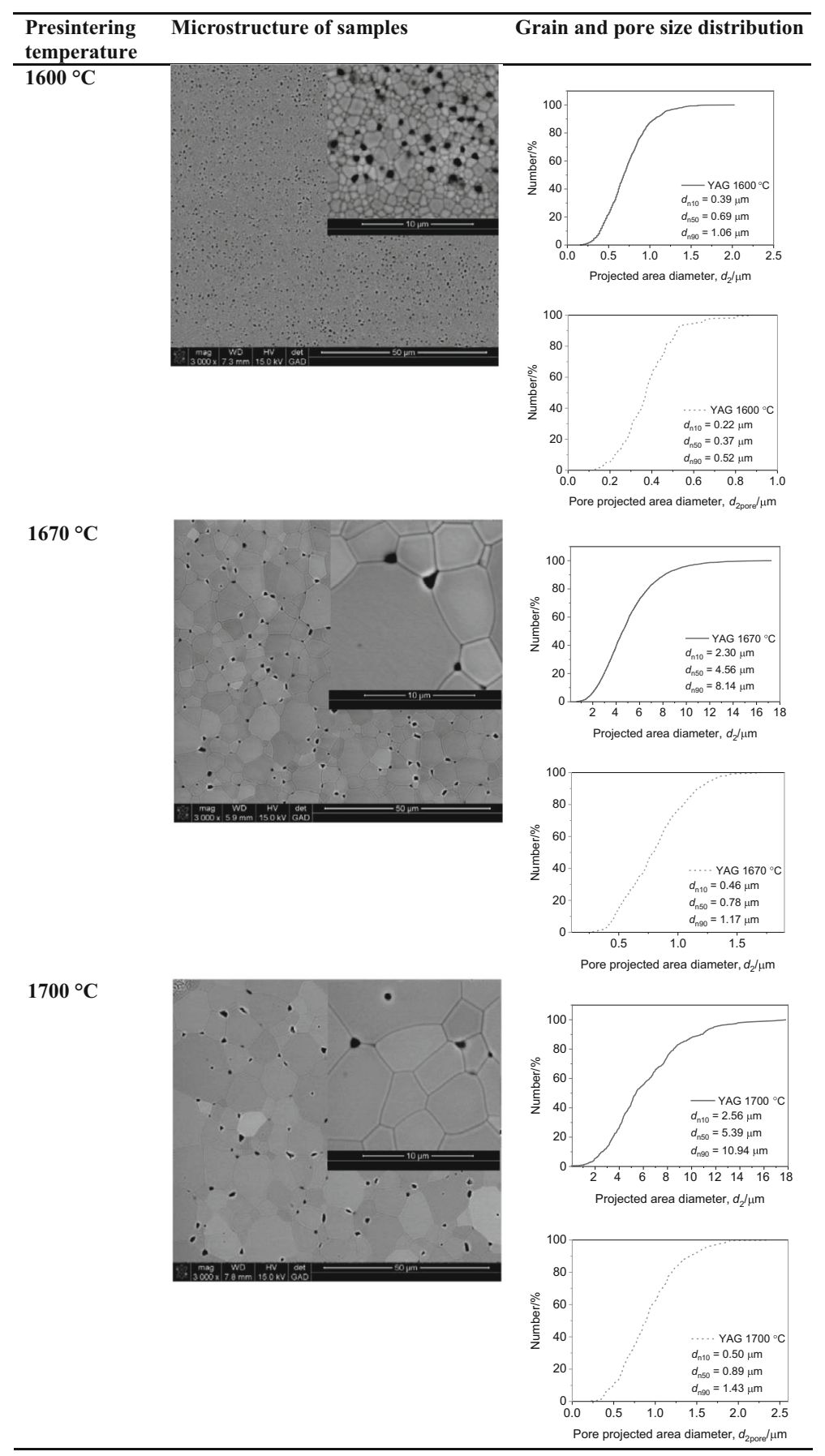


Table 5 Microstructure and grain size distribution by number of YAG samples after HIP process in selected temperatures

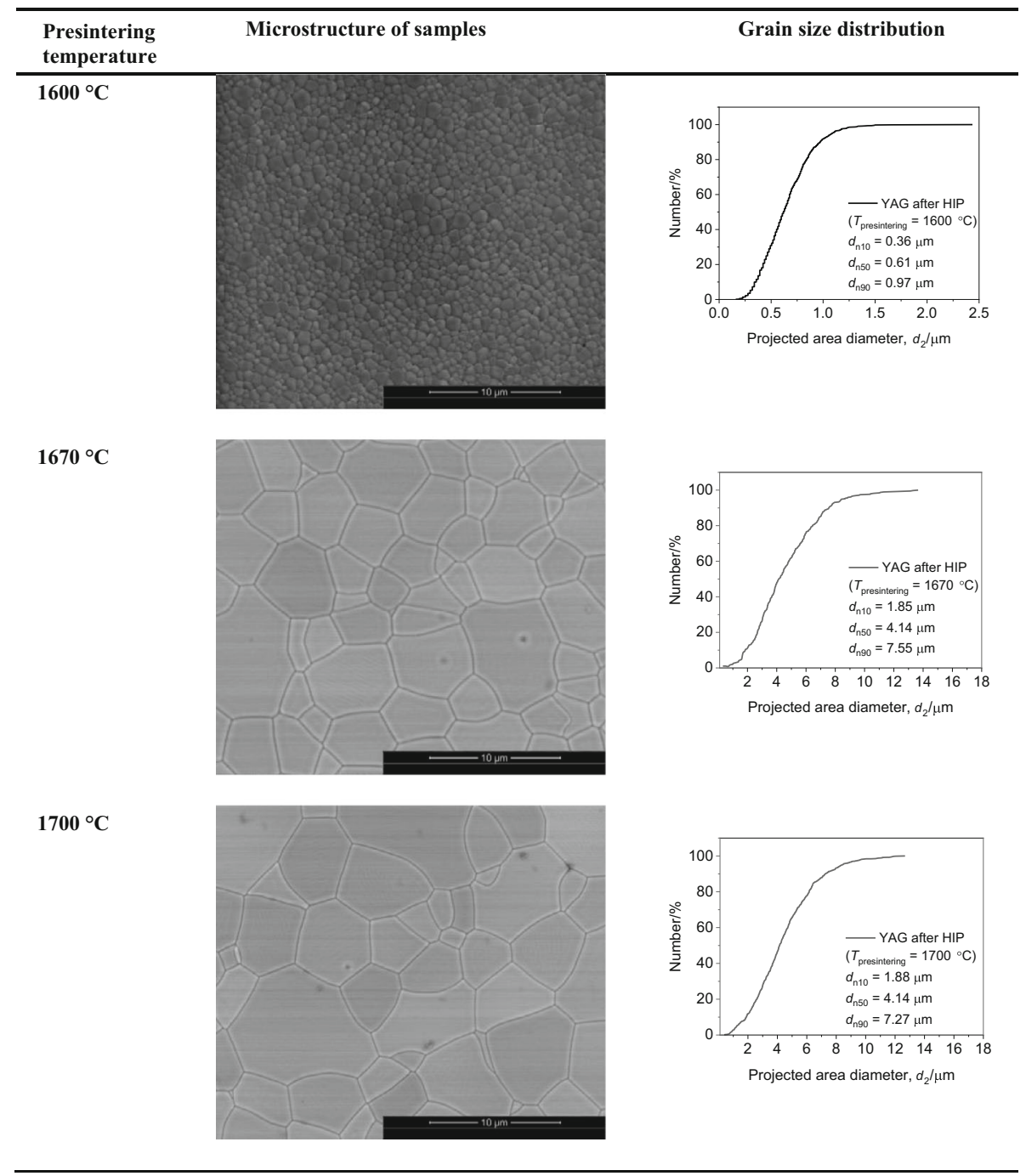

characterizing the last sintering step, i.e., onset temperature- $-1600{ }^{\circ} \mathrm{C}$, temperature of maximum linear change rate $-1670{ }^{\circ} \mathrm{C}$ and end of shrinkage process $-1700{ }^{\circ} \mathrm{C}$, were taken into account for further studies.

\section{Properties of the sintered bodies}

Based on the dilatometric analysis supported by the phase analysis in temperature, three temperatures for pressureless sintering were selected: 1600,1670 and $1700{ }^{\circ} \mathrm{C}$. The sintering was carried out for $1 \mathrm{~h}$ with a heating rate of $45^{\circ} \mathrm{C} \mathrm{h}^{-1}$. In Table 3 , density and open porosity of the presintered samples are presented.

After pressureless sintering, all samples are characterized by a relative density of above $90 \%$ and low open porosity indicating that the porosity in the bodies is closed, which qualifies the bodies for the HIP process. Density of samples after sintering at a temperature of $1600{ }^{\circ} \mathrm{C}-$ which is the onset temperature of the last sintering step-is $93.6 \%$, and after sintering at a temperature of 1670 and $1700{ }^{\circ} \mathrm{C}$, further densification takes place and the measured relative density of the samples is, respectively, 98.1 and $98.0 \%$.

In Table 4, the microstructure together with grain size distribution of the pressureless sintered samples is gathered.

Microstructural analysis shows that samples sintered at a temperature of $1600{ }^{\circ} \mathrm{C}$ possess a median grain size of $d_{2 \mathrm{n} 50}=0.69 \mu \mathrm{m}$. Samples sintered at the temperature of maximum linear change rate in the last sintering step 

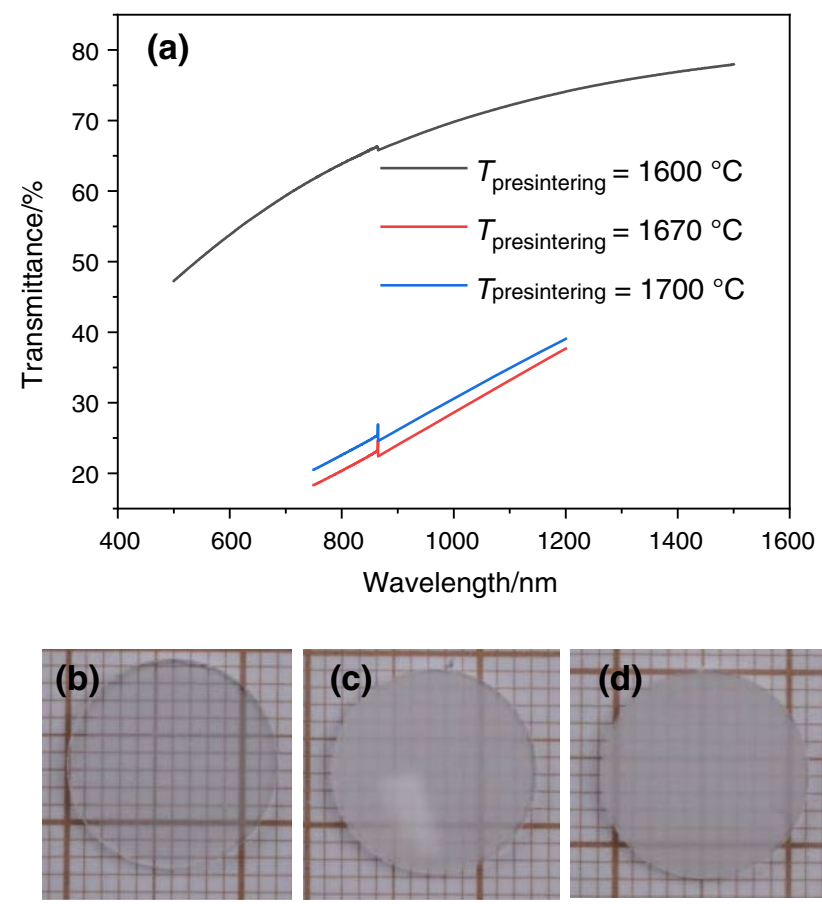

Fig. 3 Room-temperature in-line transmittance spectra (a) and general view of YAG samples after HIP process after polishing; prior to HIP process, samples were presintered at temperature of: b $1600{ }^{\circ} \mathrm{C}$, c $1670{ }^{\circ} \mathrm{C}$ and d $1700{ }^{\circ} \mathrm{C}$ (samples have $1 \mathrm{~mm}$ height)

$\left(1670{ }^{\circ} \mathrm{C}\right)$ have grains of dimensions greater by one magnitude $\left(d_{2 \mathrm{n} 50}=4.56 \mu \mathrm{m}\right)$. This means that the shrinkage observed at this temperature (Fig. 2) has its origin in grain growth, which is consistent with the earlier assumption. Further increase in sintering temperature causes a slight increase in grain size as samples sintered at a temperature of $1700{ }^{\circ} \mathrm{C}$ are characterized by average grain size of $d_{2 \mathrm{n} 50}=5.39 \mu \mathrm{m}$ (Table 4).

Pores in samples sintered at temperature of $1600{ }^{\circ} \mathrm{C}$ are of submicrometric size $\left(d_{\mathrm{n} 50}=0.37 \mu \mathrm{m}\right)$ and are placed at grains triple junctions. Sintering in higher temperatures causes not only an increase in grain size but also an increase in pore size. Pores in samples sintered at temperature of 1670 and $1700{ }^{\circ} \mathrm{C}$ have median size diameter of 0.78 and $0.89 \mu \mathrm{m}$, respectively (Table 4 ). They are placed mainly at triple junctions and grain boundaries, but there are also some pores closed in grains visible. Such microstructure is not beneficial for densification in HIP process. According to sintering thermodynamics, the energy required for pore closure is inversely proportional to pore diameter [22], and thus, it can be concluded that samples with micron-sized pores will need more energy for pore removal than those with pores of submicron size.

Samples after presintering underwent post-sintering in hot isostatic pressing (HIP). In Table 5, microstructure and grain size distribution of samples after HIP process are presented.
SEM observations of polished and etched surfaces of YAG after HIP process revealed microstructure with no visible porosity (Table 5). Grain size distribution of presintered samples is similar in comparison with the ones before HIP process. Median sizes $\left(d_{2 n 50}\right)$ of samples presintered at temperature of 1600,1670 and $1700{ }^{\circ} \mathrm{C}$ are $0.61,4.14$ and $4.14 \mu \mathrm{m}$, respectively.

The undersize curves of grain size distribution are very similar in each sample population presintered at each of the selected temperatures. A slight decrease in grain size was observed. It is claimed that brittle particles may fracture under externally applied pressure, which leads to comminution of grains [22]. In SEM images (Table 5) presenting microstructure of samples presintered at temperature of 1670 and $1700{ }^{\circ} \mathrm{C}$, some grain boundaries create sharp angle. Some longitudinal grains are visible, as well. This kind of microstructural artifacts is quite uncommon in ceramics and was not observed in samples before HIP process. This may indicate that when external pressure was applied, some grains have fractured and the uncommonly shaped grains are in fact parts of larger ones.

According to the observed microstructure, all samples should show beneficial optical properties.

In-line transmittance graph of the YAG samples after polishing and photographs are presented in Fig. 3.

Depending on presintering parameters, samples show various optical properties after HIP process. The highest transmittance was registered for the sample presintered at a temperature of $1600{ }^{\circ} \mathrm{C}$ and reaches $78 \%$ at a wavelength of $1500 \mathrm{~nm}$ and $64 \%$ at $808 \mathrm{~nm}$. This is still far from the theoretical transmittance of YAG which is $85 \%$ [29] which disqualifies these materials for laser applications, but can be sufficient for viewfinders for thermal applications. Samples sintered at higher temperatures show a much lower transmittance, and at a wavelength of $808 \mathrm{~nm}$ for samples sintered at a temperature of 1670 and $1700{ }^{\circ} \mathrm{C}$, it is 21 and $23 \%$, respectively.

\section{Conclusions}

Transparent YAG ceramics were successfully obtained using nanopowders as starting material, the main phase of which (81.74 mass\%) was hexagonal YAP phase.

Samples were formed by uniaxial pressing technique followed by isostatic pressing to a relative density of $51.2 \%$. Formed samples were then densified in a two-stage sintering process, which included pressureless presintering followed by hot isostatic pressing.

Sintering process was examined using high-temperature dilatometer supported by phase analysis vs temperature. The sintering process proceeds in three stages. 
During the first and the second steps, the phase transformation of YAP and YAM into YAG phase occurs. In the last sintering step which starts at a temperature of $1605{ }^{\circ} \mathrm{C}$, the shrinkage is connected with grain growth.

This kind of complementary measurements can be an effective tool for designing monolithic ceramics with a controlled microstructure. Therein, presented results will be applied for fabrication of doped YAG ceramics and other oxide ceramics derived from nanopowders.

Samples were presintered at temperatures of 1600,1670 and $1700{ }^{\circ} \mathrm{C}$. Samples after sintering at a temperature of $1600{ }^{\circ} \mathrm{C}$ have a relative density of $93.6 \%$ and finely grained microstructure with submicrometric pores placed at grain triple junctions. After HIP microstructure analysis of the YAG, ceramics presintered at $1600{ }^{\circ} \mathrm{C}$ revealed that the pores underwent closure, while a significant change in grain size was not observed (median of projected area diameter is $\left.d_{2 \mathrm{n} 50}=0.61 \mu \mathrm{m}\right)$. Samples obtained in this manner show in-line transmittance of $78 \%$ at a wavelength of $1500 \mathrm{~nm}$, which is sufficient for materials used in viewfinders.

After HIP process, a minor decrease in grain size and untypical microstructure were observed in samples. In order to prove the hypothesis that HIP process caused the comminution of grains, further researches should be performed, i.a., mapping of crystallographic directions of grains by EBSD technique with an emphasis on artifacts present in the microstructure, evaluation of the hardness and fracture toughness of YAG grains and modeling of stresses present during pressure-assisted sintering (HIP).

Acknowledgements This work was funded by the Polish Ministry of Science and Higher Education.

Open Access This article is distributed under the terms of the Creative Commons Attribution 4.0 International License (http://creative commons.org/licenses/by/4.0/), which permits unrestricted use, distribution, and reproduction in any medium, provided you give appropriate credit to the original author(s) and the source, provide a link to the Creative Commons license, and indicate if changes were made.

\section{References}

1. Kostić S, Lazarević ZŽ, Radojević V, Milutinović A, Romčević M, Romčević NŽ, Valčić A. Study of structural and optical properties of YAG and Nd:YAG single crystals. Mater Res Bull. 2015;63:80-7.

2. Mun JH, Novoselov A, Yoshikawa A, Boulon G, Fukuda T. Growth of $\mathrm{Yb}^{3+}$-doped $\mathrm{Y}_{2} \mathrm{O}_{3}$ single crystal rods by the micropulling-down method. Mater Res Bull. 2005;40(8):1235-43.

3. Zhang G, Jiang B, Zhang P, Jiang Y, Chen S, Zhang L. Growth mechanism of YAG single crystal in planar waveguide by solidstate crystal growth method. Ceram Int. 2018;44:18949-54.

4. Apetz R, van Bruggen MPB. Transparent alumina: a light scattering model. J Am Ceram Soc. 2003;86(3):480-6.
5. Lua J, Uedaa K, Yagib H, Yanagitanib T, Akiyamac Y, Kaminski AA. Neodymium doped yttrium aluminum garnet $\left(\mathrm{Y}_{3} \mathrm{Al}_{5} \mathrm{O}_{12}\right)$ nanocrystalline ceramics: a new generation of solid state laser and optical materials. J Alloys Compd. 2002;341:220-5.

6. Yagi H, Yanagitania T, Yoshidac H, Nakatsukac M, Uedab K. The optical properties and laser characteristics of $\mathrm{Cr}^{3+}$ and $\mathrm{Nd}^{3+}$ co-doped $\mathrm{Y}_{3} \mathrm{Al}_{5} \mathrm{O}_{12}$ ceramics. Opt Laser Technol. 2007;39:1295-300.

7. Tang F, Cao Y, Huang J, Guo W, Liu H, Huang Q, Wang W. Multilayer YAG/Re:YAG/YAG laser ceramic prepared by tape casting and vacuum sintering method. J Eur Ceram Soc. 2012;32:3995-4002.

8. Ikesue A. Polycrystalline Nd:YAG ceramics lasers. Opt Mater. 2002;19:183-7.

9. Zhang W, Lu TC, Wei N, Shi YL, Mad BY, Luo H, Zhang ZB, Deng J, Guan ZG, Zhang HR, Li CN, Niu RH. Co-precipitation synthesis and vacuum sintering of Nd:YAG powders for transparent ceramics. Mater Res Bull. 2015;70:365-72.

10. Wu Y, Li J, Qiu F, Pan Y, Liu Q, Guo J. Fabrication of transparent $\mathrm{Yb}, \mathrm{Cr}: \mathrm{YAG}$ ceramics by a solid-state reaction method. Ceram Int. 2006;32:785-8.

11. Chen Z, Li J, Xu J, Hu Z. Fabrication of YAG transparent ceramics by two-step sintering. Ceram Int. 2008;34:1709-12.

12. Fedyk R, Hreniak D, Łojkowski W, Stręk W, Matysiak H, Grzanka E, Gierlotka S, Mazur P. Method of preparation and structural properties of transparent YAG nanoceramics. Opt Mater. 2007;29:1252-7.

13. Liu K, He DW, Zhou XL, Wang HM, Lu TC, Chang J. Method of preparation and thermodynamic properties of transparent $\mathrm{Y}_{3} \mathrm{Al}_{5} \mathrm{O}_{12}$ nanoceramics. $\mathrm{J}$ Therm Anal Calorim. 2013;111(1):289-94.

14. Ring AT. Fundamentals of ceramic powder processing and synthesis. London: Academic Press; 1996.

15. Wejrzanowski T, Pielaszek R, Opalińska A, Matysiak H, Łojkowski W, Kurzydłowski KJ. Quantitative methods for nanopowders characterization. Appl Surf Sci. 2006;253:204-8.

16. Gleiter H. Nanocrystalline materials. Prog Mater Sci. 1989;33:223-315.

17. Mahdavi M, Farrokhpour H, Tahriri M. Investigation of simultaneous formation of nano-sized $\mathrm{CuO}$ and $\mathrm{ZnO}$ on the thermal decomposition of ammonium perchlorate for composite solid propellants. J Therm Anal Calorim. 2018;132:879-93.

18. Carvalho JF, De Vicente FS, Marcellin N, Odier P, Hernandes AC, Ibanez A. Synthesis of YAP phase by a polymeric method and phase progression mechanisms. $\mathrm{J}$ Therm Anal Calorim. 2009;96(3):891-6.

19. Michalik D, Sopicka-Lizer M, Plewa J, Pawlik T. Application of mechanochemical processing to synthesis of YAG: Ce garnet powder. Arch Metall Mater. 2011;56(4):1257-64.

20. Kong LB, Huang YZ, Que WX, Zhang TS, Li S, Zhang J, Dong ZL, Tang DY. Transparent ceramics. Berlin: Springer; 2015.

21. Pampuch R, Haberko K, Kordek M. Nauka o procesach ceramicznych. Warszawa: Wyd. Naukowe PWN; 1992.

22. Atkinson HV, Davies S. Fundamental aspects of hot isostatic pressing: an overview. Metall Mater Trans A. 2000;31A:2981-3000.

23. Gizowska M, Kobus I, Perkowski K, Zalewska M, Konopka G, Witosławska I, Osuchowski M, Jakubiuk K, Witek A. Otrzymywanie i charakterystyka nanoproszków $\mathrm{Y}_{3} \mathrm{Al}_{5} \mathrm{O}_{12}$ syntezowanych na drodze reakcji spaleniowej inicjowanej promieniowaniem mikrofalowym. Szkło i Ceramika. 2016;5:23-6.

24. Legros C, Carry C, Bowen P, Hofmann H. Sintering of a transition alumina: effects of phase transformation, powder characteristics and thermal cycle. $\mathrm{J}$ of the Eur Ceram Soc. 1999;19:1967-78. 
25. Lamouri S, Hamidouche M, Bouaouadja N, Belhouchet H, Garnier V, Fantozzi G, Trelkat JF. Control of the $\gamma$-alumina to $\alpha$ alumina phase transformation for an optimized alumina densification. Bol Soc Esp Ceram V5. 2017;6:47-54.

26. Kim D-W, Kim T-G, Hong KS. Origin of a shrinkage anomaly in anatase. J Am Ceram Soc. 1998;81(6):1692-4.

27. Wang R, Wang Y, Fu Z, Wang H, Wang W, Zhang J, Zhu J. Spark plasma sintering of transparent YAG ceramics assisted by the YAH-YAG phase transformation. J Eur Ceram Soc. 2016;36:2153-6.
28. Lis J, Pampuch R. Spiekanie. Wydawnictwo Akademii GórniczoHutniczej im. Stanisława Staszica. 2000.

29. Ikesue A, Lin AY, Lupei V. Ceramic lasers. Cambridge: Cambridge University Press; 2013.

Publisher's Note Springer Nature remains neutral with regard to jurisdictional claims in published maps and institutional affiliations. 